\title{
Rāranga - the art of weaving
}

\section{Tauke Kirkwood}

Tauke Kirkwood is passionate about his social work and family therapy practice within the Pupukemoana Team based at Waitemata District Health Board. He has been practicing social work for 20 years in Aotearoa, the UK and the USA. Tauke specialises in youth mental health and families. He and Yvonne have three kids and four mokopuna in their blended whannau and are grandparents raising children.

Editors note: As social work educators, one of the things the editors have noted is that there is shortage of practice framework examples of how Māori practitioners actually work in the field. One of the things we hope to do is encourage practitioners to write up how they work so that new social workers have a variety of practice examples to draw on in developing their own practice.

Hutia te rito o te harakeke

Kei hea te kōmako e kō

Kī mai ki ahau

He aha te mea nui ō te ao

Māku e ki atu

He tangata, he tangata, he tangata.

If the centre shoot of the flax is pulled out

(and the flax dies)

Where will the bellbird sing?

If you were to ask me

What is the most important thing in the world?

I would reply

It is a person, a person, a person

(that is, each and every person).

\section{Mihi}

Ko Kohukohunui te Maunga

Ko Wairoa te Awa

Ko Maraetai te Moana

Ko Tainui te Waka

Ko Ngāi Tai te iwi

Ko Umupuia te Marae

Ko Ngeungeu te whare tupuna

Ko Tara Te Irirangi te ariki ki runga

Ko Raukohekohe te whare kai

Ko St Mary's te whare karakia

Ko Mac the knife taku matua

Ko Anne taku mama.

Ko Yvonne taku wahine

Ko Michael rātou ko Katrina, Ko Holly aku tamariki

Ko Michael James rātou ko Olivia, ko Phoenix Rose, ko Lily-Belle Belle aku mokopuna.

Ko Tamaki Makaurau te papakāinga 


\section{The Raranga Harakeke programme}

Raranga Harakeke (weaving with flax) is a sensory modulation tool used by the 'Pupukemoana' team, a child and adolescent mental health team based at Waitemata District Health Board in Tamaki Makaurau. It is an effective tool that uses western sensory concepts to self-regulate and make emotional adjustments by implementing a Māori cultural perspective using flax weaving. Prior to this project there were no Māori cultural constructs / tools offered to Māori whānau by the Child Youth \& Family Mental Health Services based at Waitemata District Health Board. Raranga Harakeke provide a range of Māori values and concepts, practices and principles that can be drawn on to work effectively within whānau dynamics to assist in healing and well-being.

Raranga Harakeke draws on the symbolism of flax weaving and the importance it has both metaphorically and in practice.

Māori weaving is full of symbolism and hidden meanings. Embodied with the spiritual values and beliefs of the Māori people (Puketapu-Hetet, 1989, p.2).

Weaving is more than just a product of manual skills. From the simple rourou food basket to the prestigious kahu kiwi [kiwi feather cloak], weaving is endowed with the very essence of the spiritual values of Mãori people. The ancient Polynesian belief is that the artist is a vehicle through whom the gods create (Puketapu-Hetet, 1989, p. 2).

Of all the Māori weaving techniques, raranga is the one that has best survived colonisation. It also has the strongest links with Pacific Island weaving (Puketapu-Hetet, 1989, p. 44).

The symbolism and hidden meanings are contained in the many patterns, both ancient and modern, used in the many forms of weaving, and in the fibres themselves.

For Māori, Raranga is also a powerful symbol that evokes tribal memories of the ancestors and the arts they brought with them to Aotearoa New Zealand that they passed down to us. A living art and a living symbol that has survived with us, our language and culture, and that moves us beyond the temporary setbacks of the colonial era.

The kete itself has power as a symbol for a container of knowledge and wisdom. This is an ancient symbolism contained in the story of how Tāne-te-Wānanga obtained for all mankind the three kete of knowledge from Io, the supreme spiritual power.

Raranga evokes all these feelings. And it evokes strong feelings of unity and togetherness; the weaving together of the people into their families and tribes and into the Māori nation, and spiritually, the weaving together of all of creation into a single indivisible living wholeness.

\section{Raranga Harakeke as a sensory tool}

Relatively few studies critically regard cultural constructs when implementing sensory modulation to Māori service users and their whānau. Raranga Harakeke kaupapa provides a cultural construct using a Māori worldview, by providing holistic occupational therapy care in a respectful and collaborative way. Thus it provides opportunities for the profession to have a positive impact on the health of individuals, their whānau and, in turn, their communities, hapū and iwi. 
Tungia te ururua kia tupu whakaritorito te tupu o te harakeke.

Set fire to the overgrown bush, and the new flax shoots will spring up.

Clear away what you don't need and the good stuff will grow through.

(Whakataukī, author unknown)

The programme sought to complement the vision of western ideology of sensory modulation by incorporating culture, more specifically a Māori cultural perspective using the Raranga Harakeke weaving tradition.

Much has been written on sensory modulation approaches commonly used by occupational therapists within a mental health setting. Health professionals globally use these approaches with proven successful outcomes for service users. Miller, Reisman, McIntosh \& Simon (2001) refer to sensory modulation as:

... the capacity to regulate and organise the degree, intensity and nature of responses to sensory input in a graded and adaptive manner. This allows the individual to achieve and maintain an optimal range of performance and to adapt to challenges in daily life (p. 57).

Therefore the goal is to regulate sensory input and to 'make sense of the physical world' and the 'place of self within that world'. That is, efficient sensory modulation allows the central nervous system to regulate such things as attention and activity level by enabling one to attend to important stimuli, filter out irrelevant stimuli and modify the amount of stimulation one is exposed to. For children with a variety of developmental challenges, the process is often inefficient, demanding effort and attention with no guarantee of accuracy. By comparison healthy sensory modulation occurs automatically, unconsciously and without effort in normally developing children (Champagne, 2008).

Sensory modulation approaches is an umbrella term used to categorise a broad variety of therapeutic strategies specifically designed and utilised to promote self-organisation and positive change. There are multiple types of approaches used by health professionals, with sensory rooms just one of many approaches and strategies undertaken with service users (Champagne, 2008).

Tina Champagne is a well-known expert clinician in the occupational therapy field with research and work undertaken at national and international levels. She refers to sensory modulation approaches used within a sensory modulation programme (SMP) that consists of a variety of strategies that include sensorimotor activities and the use and development of a sensory diet, most importantly the therapeutic use of self, sensory modalities and modifications to the physical environment (Champagne, 2008).

Occupational therapists use these to help prepare, enhance and / or maintain the ability to engage actively in meaningful life roles and activities. Safe and self-nurturing activities are typically used to facilitate the creation or deepening of attractor patterns that promote resiliency and recovery.

Sensory modulation was first introduced in Aotearoa New Zealand in the early 1940s by Margaret Buchanan, the first qualified occupational therapist. Buchanan not only pursued the development of occupational therapy services, but also the development of the first training programmes as well as providing advice to government. 
In 2007, the staff at the Northland District Health Board Psychiatric Unit at Whangarei Hospital established a sensory room, the first of its kind in Aotearoa New Zealand, as part of a number of initiatives to provide practical means to reduce distress among service users and to promote a viable alternative to seclusion and restraint (Te Pou, 2009). The sensory room at Northland DHB serves to provide a place that encourages and promotes self-regulation, self-nurturing, resilience and recovery. The room is designed to tone down arousal levels and may be incorporated into the service users' treatment plan. Positive results and findings emerged in the first two years of using the sensory room, with a reduction in the use of seclusion and restraint by 50\% from 2006 to 2008 (Te Pou, 2009). Another positive result was the number of rooms used for seclusion reduced from four to two. Two other rooms were created for service users to access without the need for staff members to be present, giving service user's autonomy. Significant positive feedback from clinical staff and the consumer advisor was given and as a result of this an additional model has been created that informed the development of sensory modulation rooms in four further district health boards.

Sensory modulation has usually existed in acute mental health inpatient units, however more recently clinicians have been providing service users with sensory modulation in homes and community settings. Within the Waitemata District Health Board, the North One team designed and delivered a series of workshops in 2010 for sensory modulation to service users with a Borderline Personality Disorder diagnosis. The workshops consisted of a two-hour group session over a three-week period, where service users, their key workers or support workers, their family, whānau and friends were welcome to participate. The workshops were delivered in the occupational therapy room where exploration of practical strategies could be applied in everyday life activities, including brainstorming coping strategies and identifying what things calm or enhance their effects of distress. Each person was able to experiment with the sensory tools and practice using different strategies to moderate their level of arousal. What also made these workshops a success was the willingness of the facilitators to share their personal experiences. Giving real-life examples was a pivotal approach of personalising and normalising the skills taught in each workshop. The feedback from the workshops has enabled another set of workshop series and the team at North One to incorporate sensory modulation into service users' crisis plans and relapse-prevention plans (Dempsey 2011).

Champagne (2008) states that sensory modulation approaches are meaningful, informed by trauma, collaborative, focused on recovery and supportive of sensory growth. Furthermore, that it is a personalised process, where modifications specific to gender, age, levels of ability, individual learning needs, symptom history, spiritual and cultural considerations are included in each individual's sensory modulation strategy. However, there is lack of research and exploration in terms of cultural and spiritual components when interacting with Māori service users and their whānau. Māori mental health is an area of high priority within both Māori health and mental health. Until recently, there has been a lack of research and information about the nature and extent of Māori mental health needs, and even less is known about how effectively Māori mental health problems and disorders are managed. Currently, there are increasing concerns for young Māori and the growing rate of hospitalisation for psychiatric disorders and an increasing trend in suicide. From 2003-2004 Te Rau Hinengaro: The New Zealand Mental Health Survey (Oakley Browne, Wells, \& Scott, 2006) included 2,595 Māori participants 16 years and over. Results from the survey emphasised the importance of ongoing concerns about Māori mental health. Some key findings includ- 
ed: The most common disorders were anxiety disorders (19\%), mood disorders (11\%) and substance misuse disorders (9\%).

Contemporary health services including general practice focus on physical and psychological well-being as a measure of treatment progress or cure. For Mãori, the wairua (spiritual) wellbeing of an individual and whānau as well as the wider physical and spiritual components are paramount in the well-being of a person. The majority of health practitioners working with Māori clients and whānau use Māori health models. Two commonly used Māori health models are Te Whare Tapa Whā and Te Wheke. The fundamental basis of these models is that it incorporates a Mãori worldview which is aligned with Raranga Harakeke.

Hopkirk (2006) suggests that for many Māori service users it is important to consider, issues of belonging, who they relate to and identify with within their whānau, where they come from, their whakapapa, and the use of karakia and tikanga.

Raranga Harakeke builds on this concept of sensory modulation and provides a range of Māori values and concepts, practices and principles that can be drawn on to work effectively within the whānau dynamic to assist in healing and well-being. It is underpinned by a holistic health perspective that is inclusive of a Māori worldview. Implementing the Raranga Harakeke sensory modulation concept to Māori service users and whānau allows for exploration of whānau, whenua/ environment, wairua and spiritually, whānau ora, tikanga, whakapapa, tapu and noa. Furthermore, this concept allows for Māori to connect back to cultural identity with a sense of belonging. Displacement of oneself can also be a result of disconnection to whakapapa and for Mãori this is a vital component. Raranga Harakeke provides a space to begin building an awareness of a new set of principles and values by exploring their connection to one's whakapapa.

Raranga Harakeke is an effective tool that uses western sensory concepts to self-regulate and make emotional adjustments by implementing a Māori cultural perspective. This tool is implemented as a coping strategy that incorporates the senses of smell, taste, vision, hearing, touch and in addition the use of oral motor sense (oratory) a safe space for talking therapy to occur. It can be used to assist low arousal functioning or a high level of arousal as a tool to help the system to become alert or calm, providing a 'just-right' balance. For example, a healthy person has the ability to self-regulate by modifying their arousal levels depending on the external stimuli, therefore subconsciously being able to find the just-right balance between being alert and being calm.

Implementation of a Raranga Harakeke programme is cost effective as the majority of resources come from the natural environment. Providing holistic occupational therapy care to Māori in a respectful and collaborative way will provide opportunities for the profession to have a positive impact on the health of individuals, their whānau and, in turn, their communities, hapū and iwi. But how did we whakamana the Rāranga Harakeke programme?

\section{Pupukemoana use of Raranga Harakeke as a sensory tool}

\section{How it all got started}

The journey of the use of Raranga Harakeke started at McDonald's Akoranga Drive in Tamaki Makaurau. I had just taken my moko Lilly Belle to gymnastics at the YMCA. We 
agreed to have a little treat after the session. We were sitting down eating our kai when I noticed this wahine (Shontay Mahara) with her young tamariki and I decided to kōrero with her. She told me she had just finished doing some Raranga Harakeke at a local marae in Te Raki Pae Whenua. While talking to her I realised that this combination of touch, smell and mahi could work very well for some of our Tamariki. After some discussion I asked her would she be interested in becoming a mentor for our Pupukemoana programme at the Waitemata DHB and for her to weave her magic, so to speak, with our whānau, in particular our kōtiro and mothers,

As we were talking, I explained what we do and that my thoughts were that we could use Raranga Harakeke as a sensory modulation tool. Currently, sensory modulation is seen as a very supportive intervention for tamariki, mokopuna and whānau in child and adolescent mental health settings, and for good reason. I talked about why I felt that it would be of use in our mahi as most of our whānau who come to Pupukemoana are in need of a wide range of interventions, in particular those that are culturally constructed such as Raranga Harakeke, as there are no cultural interventions of this kind in the service. I asked Shontay if she felt that she could do this mahi to which she resounded to with a big yes.

\section{Where to now}

The idea of further developing Raranga Harakeke further and use it as a sensory modulation kaupapa came about during cultural supervision with Shontay, Karra Evans, Lorraine Stewart and Shiree Taylor. Shontay and Shiree have both run Raranga Harakeke programmes in the community.

Shontay trialled a 10-week kaupapa with two of the Pupukemoana team's whānau, which included tamariki, rangatahi, older youth, two mothers and one grandmother at various times. The kaupapa was not just for females, as two male whānau members also joined in at times. A small evaluation was done and the feedback was that 10 weeks was maybe too long, especially where a week was missed here and there, for various reasons (i.e. whānau asked that it be put off and at other times our mentor had to prioritise her work capacity), and 10 weeks had become 14 weeks. However, the feedback on the kaupapa itself was that it was great to connect with their culture and to sit and reflect on what they had done in the 10-week kaupapa.

\section{Whānau voices: Reflections from whānau.}

We decided to get some reflections from whānau who completed the 10-week Raranga Harakeke programme. We used Te Whare Tapa Whā (Durie, 1998) framework as a framework for recording whānau reflections as to the value of the course.

Taha Whānau

- Strengthening ties between us by doing karakia and waiata mea ngā pepeha.

- Feelings of happiness after our sessions as sometimes we had issues before we started but by the end we had come closer.

- Laughter and being able to create something from flax.

- Feeling proud of seeing completed taonga.

- Being able to gather flax as a whānau bought us closer and again a sense of feeling aroha and connection to our culture and the feeling of flax and the whenua earth, feeling safe and grounding. 
- Feelings of accomplishment as one.

- Feeling uplifted in sessions when sometimes feeling sad due to circumstances.

- Discussion on whakapapa/sharing and feeling safe with each other - relationships stronger.

- Starting to learn and do own pepeha - re-connecting with harakeke as a way to feel better about self.

- Whānau feel they can harvest and gather flax any time and do what they are learning for ever as way to heal, self-sooth and be connected.

- Completing putiputi using coloured flax was a highlight due to the soothing and silky texture feeling of the flax and that is was looking great / connecting and feeling Māori and proud of this.

Taha Hinengaro

- Stress level high at times but starting to set up work station doing karakia and touching the flax they had harvested and feeling grounded once again in the session.

- Started feeling more confident and becoming more familiar with harakeke and creating Mātauranga.

- Felt harakeke was soft and silky using coloured harakeke as it felt soothing fresh.

- Little kōtiro found one session a little hard to connect - once she was able to handle the flax she felt better and not so down.

- One mother felt so inspired and reconnected that she wanted to do Korowai after doing the 10 sessions.

- Increased awareness of self.

Taha Tinana

- Feeling stronger due to cutting and harvesting flax. Can feel tired after two-hour session.

- If you miss a week you feel better physically after getting back into it.

- Had kai together as a celebration and feeling happy. Our emotional being is good after working at the mahi and then having kai brings it all together. Their feelings of well-being, smelling the flax, touching the flax, cutting and weaving it all helps us to feel grounded, safe and happy. It's very soothing mahi.

- Hard work harvesting can take it out of you.

- We found it comforting and calming.

- Activating the senses felt good/ smelling the cut flax / the rough and smooth edges felt good.

- There was a rhythm to it once you got into doing it.

- Kōrero on self-care / feelings up and down for little kōtiro, at times whānau take time out for refreshments, recharge batteries with kai meeting our needs.

\section{Taha Wairua}

- Karakia before and after sessions was a way to ground us and bring us all together as a whānau and enhanced our self-esteem and closeness.

- Doing pepeha practising allows for personal growth. Sharing of mihi and waiata after karakia feeling confident.

- Whakatauāki / tikanga Māori enhancing - helps us grow in ourselves - feelings of being calm and connected.

- Feelings of comfort and good energy being together confident closer to Papatūānuku.

- Seeing each other grow from the doing of karakia and well-being of all as a whānau. 
What we gleaned from the feedback is that Raranga Harakeke amplified sensory input and modulation experiences lifted the whānau participants, and that doing Raranga Harakeke afforded a safe environment to express cultural connections that enhanced their overall identity and wairua. It highlighted that by doing Rāranga Harakeke it improves self-esteem in many life domains. That doing Raranga Harakeke can increase one's ability to nurture one's self and use it to take care of one's self in many ways. That for some it can help them cope with strong emotions in the moment and find ways through it by doing Raranga Harakeke which can be done any time of the day or night. It is a tool that can live with you forever, be built on and the expression of it is endless.

As a result of the small sample of feedback received it is clear that Raranga Harakeke can be utilised as a culturally acceptable sensory modulation occupation for whānau who come through Pupukemoana as part of the 'Wraparound Systems of Care' approach we utilise in the Pupukemoana Team.

Pupukemoana have developed a shorter, six week kaupapa which we will be trialling in the near future.

Acknowledgments. Co-contributors: Tauke Kirkwood (lead) Ngāi Tai Ki Tamaki. Shontay Mahara (Raranga practitioner) Ngā Puhi. Lorraine Stewart (support) Ngāti Ruahine. Shiree Taylor (Raranga - practitioner) Ngati Maniapoto. Karra Evans (student on placement) provided input on the Research Te Rārawa/Ngā Puhi.

\section{References}

Champagne, T. (2008). Sensory modulation \& environment: Essential elements of occupation (3rd ed.). Southampton, MA: Champagne Conferences \& Consultation.

Dempsey, A. (2011). Developing a tiered sensory modulation training package. Knowledge Exchange A Te Pou Research Project. Te Pou o Te Whakaaro Nui. Waitemata District Health Board.

Durie, M. (1998). Whaiora: Maori health development, pp. 68-74. Auckland: Oxford University Press.

Hollands, T., Sutton, D., Wright-St. Clair, V. \& Hall, R. (2015). Maori mental health consumer's sensory experience of Kapa Haka and its utility to occupational therapy practice. New Zealand Journal of Occupational Therapy, 62(1), 3-11.

http: / / www.moh.govt.nz / moh.nsf / pagesmh / 5014 / \$File/te-kokiri-mental-health-addicition-actionplan-2006-2015.pdf

Hopkirk, J. (2006). Re: Culturally Relevant Occupational Therapy: Implications for the effective use of our therapeutic selves. Occupational Therapy Insight, 27, No.5, 56. New Zealand

Iwama, M. K. (2004). Revisiting culture in occupational therapy: A meaningful endeavor. OTJR: Occupation, Participation and Health, 24(1), 2-3.

Miller, L., Reisman, J., McIntosh, D., \& Simon, J. (2001). An ecological model of sensory modulation. In S. Smith Roley, E. Blanche, \& R.

Schaaf (Eds.). Understanding the nature of sensory integration with diverse populations (pp. 57-82). San Antonio, TX: Therapy Skill Builders.

Ministry of Education (2015). Te kohi harakeke. Wellington: Ministry of Education

Minister of Health. (2006). Te Kokiri: The Mental Health and Addiction Action Plan 2006-2015. Wellington: Ministry of Health.

Ministry of Health, (2015). Maori Health Models - Te Whare Tapa Wha. Retrieved from http:/ / www.health.govt. $\mathrm{nz}$ / our-work/ populations / maori-health/maori-health-models/ maori-health-models-te-whare-tapa-wha.

Oakley Browne, M., Wells, J. \& Scott, K. (Eds). (2006). Te Rau Hinengaro: The New Zealand Mental Health Survey. Wellington, Ministry of Health.

Pihama, L. (2001). Tihei mauri ora: Honouring our voices. Mana Wāhine as a Kaupapa Māori Theoretical Framezork. Doctor of Philosophy in Education, University of Auckland

Puketapu-Hetet, E. (1989). Māori Weaving. Pitman, Indiana University, USA.

Te Pou. (2009). Sensory Modulation: One approach to reducing the use of seclusion and restraint at Northland District Health board. Te Pou o te Whakaaro Nui. https://www.tepou.co.nz/assets/images/content/your_stories/ files/story045.pdf 